\section{PILOTING OF A SOCIAL MARKETING CAMPAIGN TO REDUCE MUSCULOSKELETAL RISKS RELATED TO MANUAL MATERIALS HANDLING ON CONSTRUCTION PROJECTS}

${ }^{1} \mathrm{AM}$ Dale* ${ }^{2}{ }^{2}$ Betit, ${ }^{3} \mathrm{~S}$ Strand, ${ }^{4} \mathrm{~S}$ Schneider, ${ }^{2} \mathrm{C}$ Cain, ${ }^{5} \mathrm{D}$ Rempel. ${ }^{1}$ Division of Genera Medical Sciences, Washington University School of Medicine in St. Louis, St. Louis, MO, USA; ${ }^{2}$ CPWR-The Centre for Construction Research and Training, Silver Spring, MD, USA; ${ }^{3}$ Self-employed, USA; ${ }^{4}$ Laborers' Health and Safety Fund of North America, Washington, DC, USA; ${ }^{5}$ University of California Berkeley, Berkeley, CA, USA

\subsection{6/oemed-2018-ICOHabstracts.795}

Introduction Musculoskeletal disorders (MSD) are the most common work-related health issue among construction workers. Despite the existence of practical solutions for reducing physical exposures, prevention efforts to reduce MSDs have not been systematically adopted by most construction employers. This study will describe a social marketing campaign to promote ergonomic methods in construction safety.

Methods The Ergonomics Community of Practice, consisting of researchers, industry stakeholders, and insurance industry representatives, has developed a Pilot Ergonomics Social Marketing Program to promote safer Manual Materials Handling $(\mathrm{MMH})$ on construction sites. The work group recognised a need for contractor engagement in planning for safer $\mathrm{MMH}$ with an emphasis on; establish weight limits for lifting; and storing materials to reduce $\mathrm{MMH}$ risks. Formative work with construction contractors explored how contractors approached planning and three MMH practices. Program materials will be based on formative work results.

Results Data from 81 surveys with construction contractors showed most considered themselves knowledgeable about ergonomic hazards (85\%) and knew how to prevent them (79\%). Most contractors (57\%) reported using planning strategies to prevent $\mathrm{MMH}$ risks both before and during project work but others reported little or no planning. Interviews of 12 'positive deviant' contractors identified planning for $\mathrm{MMH}$ as a common practice, and produced descriptions of several strategies used to overcome barriers for $\mathrm{MMH}$ activities.

Discussion The development of social marketing campaign materials are based on effective $\mathrm{MMH}$ strategies that have been adopted by proactive contractors. These materials, including a planning tool, will be tested by intermediary organisations (insurers and construction organisations) with contractors. The social marketing process and preliminary result on the number of contractors who chose to implement the program, the degree the program was implemented, and whether the implementation was sustained during the pilot period will be covered in this presentation.

\section{PREVALENCE OF WORK-RELATED MUSCULOSKELETAL DISEASES AND DISABILITY IN CONSTRUCTION WORKERS IN ANKARA}

${ }^{1} S$ Yüksel, ${ }^{2} \mathrm{~N}$ Tokmak, ${ }^{3} \mathrm{Z}$ Çavuşoğlu*, ${ }^{2} \mathrm{Z}$ Ünlü, ${ }^{2} \mathrm{C}$ Tuna, ${ }^{4} \mathrm{M}$ Ünald, ${ }^{2} \mathrm{MK}$ Başarall, ${ }^{2} \mathrm{~A}$ Özlü, ${ }^{5} \mathrm{~F}$ Van Dijk, ${ }^{5} \mathrm{~F}$ Schaafsma. ${ }^{1}$ Public Health Directorate of Kocaeli, Kocaeli, Turkey; ${ }^{2}$ Public Health Institution of Turkey, Ankara, Turkey; ${ }^{3}$ Public Health Directorate of Izmir, Izmir, Turkey; ${ }^{4}$ Public Health Directorate of Ankara, Ankara, Turkey; ${ }^{5}$ Dept. of Public and Occupational Health, VU University Medical Centre, Amsterdam Public Health Research institute, The Netherlands

\subsection{6/oemed-2018-ICOHabstracts.796}

Introduction Musculoskeletal diseases (MSD) affect almost $30 \%$ of the global construction sectorworkforce. Recent studies have shown high risks in bricklayers, plasterers and carpenters. The main causes of MSD in construction workers are heavy lifting, repetitive movements and poor ergonomic working postures. However, there are no studies in Turkey assessing work-related MSD prevalence in the construction sectorand related disability in work and daily life. The aim of this study is to examine the prevalence of work related musculoskeletal symptoms and disability in manual handling construction workers active in the construction of new buildings for a city hospital in Ankara.

Methods We plan a cross-sectional study using a questionnaire on sociodemographic characteristics, risk factors at work and employment conditions, work history, health status, the Nordic Musculoskeletal Questionnaire (NMQ), and disability, as a consequence of work-related MSD, using a supervised face-toface interview method. The interviews will be performed by trained occupational health and safety specialists from the Public Health Institution of Turkey (PHIT). The study proposal has been approved by the PHITand the construction company. Workers will be asked for informed consent.

Results We will include about 1.200 Turkish workers in the construction branch in the study. The prevalence of workrelated MSD and disability will be determined, stratified for occupational groups and socio-demographic variables. Results are expected in October 2017.

Discussion The main outcome is the estimated prevalence of work-related MSDs in construction workers and associated occupational risk factors in the construction branch of Turkey. We will also analyse the effect of these disorders on the prevalence of disability in work and daily life. Based on the results, interventions for prevention will be recommended.

\section{Nanomaterials}

\section{1 \\ UPDATE OF POTENTIAL HAZARDS OF NANOMATERIALS}

${ }^{1}$ Paul A Schulte*, ${ }^{2}$ Ivo lavicoli*. ${ }^{1}$ National Institute for Occupational Safety and Health, Cincinnati, OH, USA; ${ }^{2}$ University of Naples Federico II, Naples, Italy

\subsection{6/oemed-2018-ICOHabstracts.797}

Aim of special session This session will address new findings about the potential hazards of nanomaterials.

Presenters: ${ }^{1} \mathrm{PA}$ Schulte, ${ }^{2} \mathrm{D}$ Pelclova, ${ }^{3} \mathrm{H}$ Wolff, ${ }^{4} \mathrm{E}$ Bergamaschi, ${ }^{5} \mathrm{D}$ Kehren, ${ }^{6} \mathrm{D}$ Broßell, ${ }^{6}$ I Guseva-Canu, ${ }^{7}$ I Iavicoli

${ }^{1}$ National Institute for Occupational Safety and Health, Cincinnati, $\mathrm{OH}$, United States of America

${ }^{2}$ Charles University and General University Hospital, Prague, Czech Republic

${ }^{3}$ Finnish Institute of Occupational Health, Helsinki, Finland

${ }^{4}$ University of Turin, Turin, Italy

${ }^{5}$ German Federal Institute for Occupational Safety and Health (BAuA), Berlin, Germany

${ }^{6}$ University of Lausanne, Lausanne, Switzerland

${ }^{7}$ University of Naples Federico II, Naples, Italy

\section{1a OVERVIEW -UPDATE OF POTENTIAL HAZARDS OF ENGINEERED NANOMATERIALS}

PA Schulte. National Institute for Occupational Safety and Health, Cincinnati, OH, USA

10.1136/oemed-2018-ICOHabstracts.798 
There is a growing body of literature examining potential hazards of engineered nanomaterials. This session will take stock of some of that literature and in particular, consider High Aspect Ratio Nanomaterials (HARNs) and more specifically carbon nanotubes. The first part of the session will address the oxidative/stress effects of various metallic nanoparticles. This will be followed by a discussion of a Horizon 2020 project known as BIORIMA. BIORIMA is a multinational collaboration to assess hazards of nano biomaterials and develop appropriate risk management tools. The remaining presentations will focus on a range of issues related to HARNs. These include assessing the similarities between carbon nanotubes (CNT) and asbestos, the identification of molecular initiating events of CNT in biological systems, the role of fibre rigidity in toxicity, mechanisms of CNT-induced inflammation, dustiness as a risk group strategy, the state of knowledge on occupational exposures, and risk management. Clearly there are many types of CNT in commerce and it is difficult to characterise the hazard with a single description. These sessions will help to identify the many factors that need to be considered.

\section{1b NONINVASIVE BIOMONITORING OF 3 GROUPS OF NANOMATERIALS WORKERS WITH ELEVATED MARKERS OF OXIDATIVE STRESS AND INFLAMMATION}

${ }^{1} \mathrm{D}$ Pelclova* ${ }^{2} \mathrm{~V}$ Zdimal, ${ }^{3} \mathrm{~S}$ Dvorackova, ${ }^{2} \mathrm{~S}$ Schwarz ${ }^{2} \mathrm{O}$ Ondracek, ${ }^{4} \mathrm{M}$ Komarc ${ }^{1} \mathrm{~S}$ VIckova, 'Z Fenclova, ${ }^{2} \mathrm{O}$ Makes, ${ }^{1} \mathrm{~S}$ Zakharov. ${ }^{1}$ Charles University and General University Hospital in Prague, First Faculty of Medicine, Department of Occupational Medicine, Prague, Czech Republic; ${ }^{2}$ Institute of Chemical Process Fundamentals of the CAS, Praque, Czech Republic; ${ }^{3}$ Technical University in Liberec, Faculty of Mechanical Engineering, Department of Machining and Assembly, Department of Engineering Technology, Department of Material Science, Liberec, Czech Republic; ${ }^{4}$ Charles University in Prague and General University Hospital in Prague, First Faculty of Medicine, Institute of Biophysics and Informatics, Prague, Czech Republic

\subsection{6/oemed-2018-ICOHabstracts.799}

Introduction The studies of workers exposed to nanomaterials are rather rare; however, the data are urgently needed, as the experimental data bring suspicion on deleterious effect by inhalation. The aim was to examine non-invasively workers exposed to varied materials, containing nanoparticles, and compare the results of the same markers of oxidation of lipids, nucleic acids and proteins, in addition to spirometry and fractional exhaled nitrogen oxide (FeNO).

Methods Three groups of workers were examined and compared with comparable control groups. They included:

- total 34 nanoTiO2 workers in two consecutive years

- 14 nano Fe oxides and

- total 32 nanocomposites workers in two consecutive years.

Aerosol exposure in nanocomposites was measured using offline and online aerosol instruments: Berner Low-Pressure Impactor, Scanning Mobility Particle Sizer, Aerodynamic Particle Sizer, Condensation Particle Counter and Optical Particle Sizer.

Following markers were analysed in the exhaled breath condensate (EBC) by liquid chromatography-electrospray ionization-tandem mass spectrometry (LC-ESI-MS/MS): malondialdehyde, 4-hydroxy-trans-hexenal, 4-hydroxy-trans-nonenal, 8isoProstaglandinF2 $\alpha$, C6-C13, 8-hydroxy-2-deoxyguanosine, 8hydroxyguanosine, 5-hydroxymethyl uracil, o-tyrosine, 3-chlorotyrosine, 3-nitrotyrosine and proinflammatory leukotrienes
LTB4, LTC4, LTE4, LTD4. Fractional exhaled nitric oxide (FeNO) and spirometry were measured.

Results The exposure to inert dusts exposure did not exceed allowed gravimetric limits for occupational exposure. However, all workers had elevated markers of oxidative stress, as compared to the controls. LTB4 and cysteinyl LTE4 were most involved inflammation markers. Most elevated markers were seen in nanoTiO2 workers, lower effect was seen both in the nano $\mathrm{Fe}$ oxides and nanocomposites exposed workers. On the other hand, spirometry and FeNO did not show any significant impairments.

Conclusions Non-invasive biomonitoring using markers of oxidative stress, LTB4 and LTE4 may be most useful and could be recommended biomarkers for preventive examinations and monitoring of workers with occupational exposure to nanoparticles.

Acknowledgement Progres Q25/1LF, Q296/1LF, 43/17/RPZP and CSFP503/12/G147.

\section{C THE POTENTIAL CARCINOGENICITY OF CARBON NANOTUBES (CNTS): SIMILARITIES AND DIFFERENCES WITH THE PATHOGENESIS OF ASBESTOS RELATED CANCERS}

H Wolff. Finnish Institute of Occupational Health, Helsinki, Finland

\subsection{6/oemed-2018-ICOHabstracts. 800}

Introduction Cancers and other diseases caused by asbestos and has led to the 'fibre paradigm' that in essence suggests that biopersistent, fibre like, materials have a potential for asbestos-like negative health effects. The overwhelmingly most common type of fiber-like nanomaterials are the carbon nanotubes (CNTs) of which there are numerous types. As predicted by the paradigm some CNTs have been shown to elicit tumour formation in animal models. Because of the very broad variety of CNTs it is imperative to understand which of these will have asbestos like effects. There are also unanswered questions about the carcinogenicity of CNTs that are not asbestos-like.

Methods The presentation will discuss asbestos related carcinogenicity and evaluate the differences and similarities to the current understanding of CNT related carcinogenesis. Special attention will be paid to in vivo studies and histology. In addition to discussing published literature some unpublished results will also be presented.

Results The early phases of asbestos induced effects in vivo include activation of inflammatory cascades and the production of reactive oxygen species. These effects are not that specific for asbestos and can be found in association with silica exposures and other exposures, including nanomaterials. A somewhat specific feature of asbestos exposure is a in vivo is eosinophilia associated with a Th2 type of immunological response. Interestingly this type of reaction can be seen in some types of CNTs with physical properties reminiscent of asbestos.

Discussion Some CNTs do have physicochemical properties and an in vivo inflammatory response similar to that of asbestos. The potential for carcinogenicity of CNTs without these asbestos-like features is rather poorly investigated. Additional studies with traditional animal models for carcinogenicity are needed to provide a foundation for other approaches to determine carcinogenic potential. 